\title{
BMJ Open Study protocol for a natural experiment in a lower socioeconomic area to examine the health-related effects of refurbishment to parks including built-shade (ShadePlus)
}

S J Dobbinson, ${ }^{1} \mathrm{~J}$ Veitch, ${ }^{2} \mathrm{~J}$ Salmon, ${ }^{2} \mathrm{M}$ Wakefield, ${ }^{1} \mathrm{P}$ K Staiger, ${ }^{3} \mathrm{R} \mathrm{J}$ Macinnis,,${ }^{1,4}$ J Simmons ${ }^{1}$

To cite: Dobbinson SJ, Veitch J, Salmon J, et al. Study protocol for a natural experiment in a lower socioeconomic area to examine the health-related effects of refurbishment to parks including built-shade (ShadePlus). BMJ Open 2017;7:e13493.

doi:10.1136/bmjopen-2016013493

- Prepublication history and additional material is available. To view please visit the journal (http://dx.doi.org/ 10.1136/bmjopen-2016013493).

Received 19 July 2016 Revised 2 December 2016 Accepted 26 January 2017

CrossMark

For numbered affiliations see end of article.

Correspondence to Dr S J Dobbinson; Suzanne. Dobbinson@cancervic.org.au

\section{ABSTRACT}

Introduction: Parks in disadvantaged suburbs often have low quality and few amenities, which is likely to result in them being underutilised for recreation and physical activity. Refurbishment of parks, including shade, walking paths and other amenities, may have broad health-related benefits.

Methods and analysis: The study design, methods and planned analyses for a natural experiment examining the effects of refurbishments including builtshade added to parks in disadvantaged outer suburbs of Melbourne are described. Three intervention parks and three comparison parks matched for equivalence of park and neighbourhood characteristics were selected. Using mixed methods, the outcomes will be assessed during three consecutive spring-summer periods (T1: 2013-2014; T2: 2014-2015: T3: 2015-2016). Primary outcomes included: observed park use, physical activity and shade use. Self-reported social connectedness, community engagement and psychological well-being were assessed as secondary outcomes.

Ethics and dissemination: This study was approved by Cancer Council Victoria's Human Research Ethics Committee. Studies such as ShadePlus can improve understanding of the broader effects of park refurbishments (including physical activity levels and sun protection behaviours, as well as social connectedness and psychological well-being). The study findings will be disseminated through established urban planning and parks and recreation networks, peer review publications and conference presentations.

\section{INTRODUCTION}

The benefits of increasing physical activity levels for prevention of obesity, diabetes and cardiovascular disease are well recognised. ${ }^{12}$ Public health proponents have started action to reduce sedentary lifestyles among the

\section{Strengths and limitations of this study}

- ShadePlus will contribute to knowledge of the health-related effects of refurbishments to parks (including shade and walking paths) on socioeconomically disadvantaged areas.

- This natural exposure experiment will enable us to examine both short-term and long-term effects across three consecutive time periods (in spring-summer months before, after and follow-up).

- The study design includes three intervention parks selected from those prescheduled to receive refurbishments and three comparison parks matched for equivalence of park and neighbourhood characteristics, which gives us sufficient power to detect meaningful differences between the two groups. However, there is potential bias due to non-randomised group selection.

- We will be able to assess a broad range of outcome measures (including observed park use, physical activity and sun protection behaviour) based on reliable tools using a mixed methods approach.

- To the best of our knowledge, ShadePlus is the first study evaluating the effects of modifying the built environment on both physical activity levels and sun protection behaviours, as well as social connectedness and psychological well-being.

population, including promoting physical activities in outdoor settings such as parks. ${ }^{3-5}$ Given this increased focus on bringing people outdoors for physical activity, it is imperative to encourage sun protection in tandem with physical activity. ${ }^{3}{ }^{6}$ This is especially relevant for countries like Australia, where exposure to high solar ultraviolet radiation (UVR) causes a significant public health burden. ${ }^{7}$ 
Parks can be an important setting for recreation and physical activity. ${ }^{4-12}$ Moreover, contact with greenery and open space has been found to reduce psychological distress. ${ }^{13}$ Significant disparities in the quality and number of facilities have been observed in an audit of 1500 parks in Melbourne, Australia. ${ }^{14}$ That study showed that parks located in suburbs of relatively socioeconomically disadvantaged communities had poorer quality and fewer facilities including trees, shade, water features, walking paths, lighting and dog signage. Given the evidence of lower physical activity levels ${ }^{15}$ and poorer health outcomes for residents of socioeconomically disadvantaged areas, ${ }^{16-18}$ and likely benefits of increased contact with greenery and open space, ${ }^{10} 13$ strategies such as park refurbishments to improve satisfaction with recreational amenities and increase park usage may have a broader health benefit for these communities.

Socioecological models have been developed to describe how health-related behaviours are shaped by numerous influences at multiple levels, from individuals' beliefs and predispositions, to their social networks and the broader environment (political, built and natural). ${ }^{19-21}$ The Ottawa Charter ${ }^{22}$ and healthy cities movements ${ }^{23}$ have promoted the important role of the built environment in creating supportive environments for health. Improving the quality and amenity of degraded neighbourhood parks in disadvantaged areas is consistent with these paradigms.

Recent systematic reviews of built environment interventions for physical activity and other health-related outcomes have highlighted that few studies have specifically targeted improvement of parks in disadvantaged areas. $^{24} 25$ Of the park refurbishment studies in disadvantaged areas, two found increased attendance and physical activity after the refurbishments, ${ }^{26}{ }^{27}$ one found that attendance was unchanged but physical activity declined ${ }^{28}$ while another implemented both education programmes and park refurbishments and found increased attendance at the park and an increase in people engaged in vigorous physical activity on playfields. ${ }^{29}$ There is also a gap in assessment of the impact of park refurbishments on broader health-related outcomes including psychological well-being, social and community engagement, and sun exposure.

Park refurbishments that include quality built shade have the potential to benefit both physical activity levels and sun protection behaviours. Results from our previous trial of built shade in secondary schools suggested that adding shade-sails (in a visually appealing design that provided visible light and warmth as well as shade) to passive recreation areas attracted adolescents to use newly shaded areas in spring and summer months. ${ }^{30} \mathrm{We}$ hypothesise that the park setting would be amenable to similar or better outcomes for built shade, given that adults and children use parks and are typically less resistant to sun protection messages than adolescents (SJ Dobbinson, KM Jamsen, K Francis, et al. 2006-07
National Sun Protection Survey Report 2. Australians' sun protective behaviours and sunburn incidence on summer weekends, 2006-07 and comparison with 200304 in the context of the first national mass media campaign (unpublished). Melbourne, Australia: Prepared for the Australian Government Department of Health and Ageing, and The Cancer Council Australia in consultation with a national collaborative research group, Centre for Behavioural Research in Cancer, The Cancer Council Victoria, 2008. (accessed May). ${ }^{31}$ Further, playgrounds are a prime area within parks to increase shade levels, given that playgrounds have been associated with some of the highest levels of physical activity for children. ${ }^{5} 32$ Local government representatives, during recruitment for a recent randomised trial in Melbourne parks, have advised that community demand for shade is high, especially over children's playgrounds. ${ }^{33} 34$

In order to attract increased patronage, a park refurbishment would also ideally incorporate a number of other features identified as being likely to increase local residents' perceptions of the attractiveness of the parks (eg, water attractions, shade, swings and cleanliness ${ }^{34}$ ) and use for physical activity (eg, trails/walking paths, number of facilities, ${ }^{35}{ }^{36}$ lighting and dog signage, ${ }^{36}$ and playgrounds $\left.{ }^{35}{ }^{37}\right)$. In Melbourne, Australia, refurbishment of neighbourhood parks is typically the responsibility of local governments who have variable funding for this purpose. Funding for parks and their maintenance must compete with other services and infrastructure provided for residents. Providing strong evidence that quality park facilities can increase park usage, promote adoption of health behaviours, improve social connectedness and reduce psychological stress may assist local governments to place greater priority on funding these developments for communities in these disadvantaged areas.

There is often limited scope to conduct such large-scale environmental changes in the context of a randomised trial. An alternative is to establish partnerships with urban designers in local government to examine the health-related effects of planned park refurbishments. In this paper, we describe the study protocol for the ShadePlus intervention that uses the latter approach.

\section{Study aims and hypotheses}

This study aims to examine the impact of park refurbishments including built-shade in degraded parks located in socioeconomically disadvantaged areas of Melbourne, on park use, physical activity levels, shade use, other sun protection behaviours, social connectedness, community engagement and psychological well-being of park visitors and residents. A natural experiment will be used to evaluate the impact of the refurbishments at three intervention parks compared with matched comparison parks using a mixed method approach.

Our primary hypothesis is that adding shade, a walking path and other facilities to the intervention 
parks (which had few amenities present before the refurbishment) will result in a considerable increase in park use, shade use and physical activity of park visitors compared with matched comparison parks not receiving the intervention.

We also anticipate broader effects of the park refurbishments compared with the comparison parks (ie, secondary aims) including: (1) increased psychological well-being of park visitors; (2) increased perceived social connectedness and community engagement of park visitors and residents; (3) an increase in the number of park visitors who perceive the park and amenities to be attractive; and (4) improved sun protection behaviours of park visitors.

\section{METHODS AND ANALYSIS}

Establishing a research partnership with local government

With interest and letters of support for the study from the peak body for local government (the Municipal Association of Victoria) and the Victorian Department of Human Services, five local government councils located in socioeconomically disadvantaged areas of outer Melbourne were initially invited to participate in the study. The study required local governments to have planned refurbishments to degraded parks or those with few amenities scheduled within the proposed study period, and a willingness to include built-shade over children's playgrounds and/or picnic tables, new walking paths and other facilities such as playground equipment, drinking fountains, dog management and drought tolerant plantings in their refurbishments. Initially, two local government councils expressed interest in participation, but when specific parks were identified as potentially eligible for the study, only one had a budget for refurbishment that suited the study time frame. Accordingly, a partnership was established with Brimbank City Council to develop and implement the intervention.

The City of Brimbank is located in Melbourne's drought-prone outer western suburbs. It has a culturally diverse population of $\sim 185000$ residents in $2009 ;^{38}$ and it includes suburbs within the lowest decile of area socioeconomic disadvantage scores in Melbourne. ${ }^{38}$ This council has an ongoing programme of refurbishments to the neighbourhood parks it maintains.

A steering committee with representatives from Brimbank City Council, the Municipal Association of Victoria and the Department of Human Services was established to ensure shared vision of refurbishment designs, and to assist with dissemination and uptake of study findings to urban planners and policymakers at the completion of the study.

\section{Study design}

In a non-randomised pre-post controlled trial (figure 1), the impact of the ShadePlus intervention on the hypothesised outcomes described earlier will be prospectively assessed. The impact of the intervention was initially planned to be evaluated across two consecutive spring/summer periods; $\mathrm{t}_{1}$ : 2013-2014 (pretest) and $\mathrm{t}_{2}$ : 2014-2015 (post-test). Data collection measures to assess sustainability in a second spring/summer period after the refurbishments ( $\mathrm{t}_{3}$ : 2015-2016 (follow-up)) later became feasible.

The intervention effects will be assessed on a broad range of health-related and behavioural measures collected through mixed methods. Identical measures were used at all six study parks and included: (1) Observations and intercept surveys of visitors at the parks (conducted in pretest $\left(t_{1}\right)$, post-test $\left(t_{2}\right)$ and follow-up ( $\left.\left.\mathrm{t}_{3}\right)\right)$; (2) Self-report surveys of residents living within a nearby catchment of the parks (conducted in pretest $\left(\mathrm{t}_{1}\right)$ and post-test $\left.\left(\mathrm{t}_{2}\right)\right)$; and (3) Focus groups with park visitors and nearby residents (conducted after post-test $\left(\mathrm{t}_{2}\right)$ and follow-up $\left.\left(\mathrm{t}_{3}\right)\right)$.

\section{Selection of study parks}

In consultation with the City of Brimbank urban designer, suitable parks for the study were identified. The intervention parks were selected from suburbs in

\begin{tabular}{|c|c|c|c|}
\hline & $\begin{array}{c}\text { Pre-test }\left(t_{1}\right) \\
2013-2014\end{array}$ & $\begin{array}{c}\text { Post-test }\left(t_{2}\right) \\
2014-2015\end{array}$ & $\begin{array}{c}\text { Follow-up }\left(t_{3}\right) \\
2015-2016\end{array}$ \\
\hline \multicolumn{4}{|l|}{ Assessments } \\
\hline Park intercept surveys & $\longrightarrow$ & 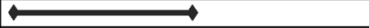 & 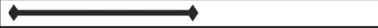 \\
\hline Residents' surveys & $\Leftrightarrow$ & $\mapsto$ & \\
\hline Focus group discussions & & $\longmapsto$ & $\longmapsto$ \\
\hline Park 1 - Dalton & 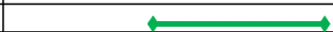 & & \\
\hline Park 2 - Wahgunyah & 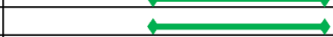 & & \\
\hline Park 3 - Calder Rise & 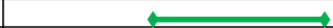 & & \\
\hline \multicolumn{4}{|l|}{ Comparison park 1} \\
\hline \multicolumn{4}{|l|}{ Comparison park 2} \\
\hline Comparison park 3 & & & $\rightarrow$ \\
\hline
\end{tabular}

Key

Measures:

Intervention: $\longleftrightarrow$

Figure 1 Study schedule. 
established areas of Brimbank where minimal construction of new housing was occurring, prioritising parks in more disadvantaged suburbs of Brimbank where feasible. The urban designer and chief investigator of the research study visited neighbourhood parks scheduled for refurbishment within the study time frame (ie, March-June 2014) to review existing condition and amenities, and to discuss the planned refurbishments. Three intervention parks were identified as meeting the study eligibility criteria, namely, having inadequate and/ or a limited number of park facilities (eg, scope for walking paths to be improved) and having inadequate shade. All parks selected had minimal shade across the whole park, and specifically no effective shade (from either natural sources or built-shade structures) in key activity areas of the parks such as playgrounds, picnic areas and seats. The detailed characteristics of the parks are described in table 1.

Subsequently, in consultation with the urban designer, a comparison park was selected for each intervention park that was matched for extent, type and condition of amenities, equivalence of park size and avoiding parks with sports grounds and planned tree plantings. The selection also aimed to achieve similarity in housing type (eg, density, age) and broad demographics between the intervention and comparison parks' neighbourhoods. We initially aimed to include comparison parks within the same suburb or adjacent suburbs, with at least $4 \mathrm{~km}$ from other parks in the study, and not too close to other nonstudy parks that had recent refurbishments. Table 1 shows that it was not feasible to achieve the intended distance between matched pairs for every park in the study (ie, two intervention-comparison pairs were $<4 \mathrm{~km}$ apart). However, the park pair with the least distance $(1.1 \mathrm{~km})$ was separated by a major road, which would limit the potential for contamination of the intervention park (ie, local residents would be less likely to use a park on the other side of a major road). The local government agreed to make no changes to amenities within the selected comparison parks from 2013 to February 2015 (ie, the originally planned pretest $\left(t_{1}\right)$ post-test $\left(t_{2}\right)$ periods). However, playground equipment was unexpectedly replaced at one of the comparison parks in early November 2015, prior to initiation of data collection for follow-up $\left(\mathrm{t}_{3}\right)$. Therefore, impact will be assessed on both intention-to-treat and parks receiving refurbishments.

\section{Intervention}

Given that the intervention parks were selected based on existing plans for park refurbishments, there was limited scope for major changes to the intervention components. However, the urban design team at Brimbank City Council was responsive to the research team's suggestions about inclusion of built-shade, and changes regarding position/type of some facilities to be provided at the parks. Figure 2 describes the intervention components implemented at the intervention parks. The facilities considered essential to the
ShadePlus intervention were inclusion of high-quality shade for either a picnic area and/or children's playground, upgrading a children's playground to provide new and engaging equipment for children's activities, a walking path and a range of other refurbishments (eg, seating, fitness circuit, flying fox, drought tolerant plantings and $\operatorname{dog}$ management). The ongoing care and maintenance of these park facilities is to be undertaken by Brimbank City Council.

\section{Measures}

The observations and self-report surveys used measures that were reliable and valid, sourced from the published literature and supplemented with a few new measures. All measures underwent a pilot test with uninvolved research colleagues to assess length and comprehension. A summary of the constructs used in the self-report surveys (park intercept, and adults' and proxy children's residents' surveys) and example items is presented in the online supplementary appendix 1. Figure 3 describes the broader domains considered in developing the measures as likely to be influenced by park refurbishments and outcomes.

The observational measures include the System for Observing Play and Recreation in Communities measure of physical activity levels ${ }^{12} 3940$ and a measure of sun protection used to observe these behaviours in parks. ${ }^{41}$ The psychological well-being of park visitors and residents was assessed in the self-report surveys with two psychometrically reliable instruments: the Positive and Negative Affect Schedule (PANAS) emotional state scale ${ }^{43} 44$ during the park intercept surveys and the Warwick Edinburgh Mental Well-being scales ${ }^{45}$ in the residents' surveys. A new set of items was developed to assess social connectedness/engagement among park visitors while at the park. Specifically, park visitors were asked about the frequency with which they had met or talked to others or attended social events while at the park in the past 3 months.

\section{Procedures}

Park audit

Research staff conducted audits of amenities (type and condition) at each park at the start of each test-period using validated facilities audits ${ }^{36}$ adapted for the study. Briefly, the procedure involved two research staff taking photographic records of park conditions on arrival at each park followed by completion of the audit. The audit included measures of accessibility, safety items (including light sources, location of houses facing the park, etc), aesthetics and the inclusion of dog areas and signage. It also assessed the presence and condition of amenities (including drinking fountains, shade sources, seats and tables, BBQs, etc), paths, activity/sporting areas and playground facilities. The audit also included the quantification and assessment of the extent of shade and the type of shade (ie, shade-sails, roofed structures, other man-made structures, natural shade and any 
Table 1 Characteristics of study parks

\begin{tabular}{|c|c|c|c|c|c|c|c|c|c|c|}
\hline $\begin{array}{l}\text { Park name (Ix/C } \\
\text { group and matched } \\
\text { pair number) }\end{array}$ & $\begin{array}{l}\text { Park } \\
\text { Size* } \\
\mathbf{m}^{2}\end{array}$ & $\begin{array}{l}\text { Walking } \\
\text { distance } \\
\text { from C } \\
\text { park }\end{array}$ & Park amenities at pretest & $\begin{array}{l}\text { Park } \\
\text { catchment } \dagger \\
\text { population } \\
\text { and density } \\
\text { (p/ha) }\end{array}$ & $\begin{array}{l}\text { Park } \\
\text { catchment } \dagger \\
\% 0-19 \text { years }\end{array}$ & $\begin{array}{l}\text { Park catchment } \dagger \\
\text { weekly personal } \\
\text { income } \leq \$ 599 \text { (less } \\
\text { than city median) }\end{array}$ & $\begin{array}{l}\text { Suburb } \\
\text { population } \neq \\
\text { and density } \\
\text { (p/ha§) }\end{array}$ & $\begin{array}{l}\text { Suburb } \\
\text { median } \\
\text { age }\end{array}$ & $\begin{array}{l}\text { Suburb } \\
\text { median } \\
\text { weekly } \\
\text { household } \\
\text { incomeł }\end{array}$ & Suburb \\
\hline $\begin{array}{l}\text { Dalton (Ix park } \\
\text { Pair 1) }\end{array}$ & 16315 & $3.5 \mathrm{~km}$ & $\begin{array}{l}\text { Small playground in good condition ( } 1 \text { swing } \\
\text { set, } 1 \text { small climbing apparatus with slide, } 1 \\
\text { rocker) bench seat, rubbish bin, small path }\end{array}$ & $6628(28.0)$ & $25 \%$ & $51 \%$ & $\begin{array}{l}16743 \\
(17.41)\end{array}$ & 37 years & $\$ 945$ & $\begin{array}{l}\text { Sunshine } \\
\text { West }\end{array}$ \\
\hline $\begin{array}{l}\text { Lowe Reserve } \\
\text { (C park } \\
\text { Pair 1) }\end{array}$ & 6471 & $3.5 \mathrm{~km}$ & $\begin{array}{l}\text { Small playground in good condition ( } 1 \text { swing } \\
\text { set, } 1 \text { slide, } 2 \text { climbing apparatuses, } 2 \\
\text { rockers), picnic bench, mini basketball court, } \\
2 \text { bench seats, rubbish bin, small path }\end{array}$ & 7820 (27.3) & $24 \%$ & $47 \%$ & $\begin{array}{l}8838 \\
(11.04)\end{array}$ & 34 years & $\$ 986$ & Sunshine \\
\hline $\begin{array}{l}\text { Wahgunyah } \\
\text { (Ix park } \\
\text { Pair 2) }\end{array}$ & 23532 & $1.1 \mathrm{~km}^{*}$ & $\begin{array}{l}\text { Small playground in good condition ( } 1 \text { swing } \\
\text { set, } 1 \text { small climbing apparatus with slide, } 2 \\
\text { rockers), } 1 \text { bench seat, rubbish bin, } 1 \text { open } \\
\text { dog off-lead area }\end{array}$ & 5695 (33.4) & $29 \%$ & $48 \%$ & $\begin{array}{l}35091 \\
(26.91)\end{array}$ & 36 years & $\$ 865$ & St Albans \\
\hline $\begin{array}{l}\text { Cowper Reserve } \\
\text { (C park } \\
\text { Pair 2) }\end{array}$ & 5650 & $1.1 \mathrm{~km}$ & $\begin{array}{l}\text { Small playground in good condition ( } 1 \text { swing } \\
\text { set, } 1 \text { monkey bars, } 1 \text { small climbing } \\
\text { apparatus with slide, } 2 \text { rockers), small } \\
\text { paths, small mini basketball court, } 2 \text { bench } \\
\text { seats, rubbish bin }\end{array}$ & $4992(32.0)$ & $23 \%$ & $50 \%$ & $\begin{array}{l}35091 \\
(26.91)\end{array}$ & 36 years & $\$ 865$ & St Albans \\
\hline $\begin{array}{l}\text { Calder Rise } \\
\text { (Ix park } \\
\text { Pair 3) }\end{array}$ & 23532 & $5.6 \mathrm{~km}$ & $\begin{array}{l}\text { Large upgraded playground in excellent } \\
\text { condition ( } 1 \text { swing set, } 2 \text { slides, boat rocker, } \\
\text { hammock, climbing wall, activity panel), mini } \\
\text { basketball court, picnic tables, BBQ, small } \\
\text { circuit walking path }\end{array}$ & $3828(19.1)$ & $21 \%$ & $35 \%$ & $\begin{array}{l}8313 \\
(8.8)\end{array}$ & 43 years & $\$ 1353$ & Keilor \\
\hline $\begin{array}{l}\text { International Gardens } \\
\text { (C park } \\
\text { Pair 3) }\end{array}$ & 28645 & $5.6 \mathrm{~km}$ & $\begin{array}{l}\text { Small playground in good condition ( } 1 \text { swing } \\
\text { set, } 1 \text { small climbing apparatus with slide), } \\
\text { small mini basketball court, } 6 \text { bench seats, } \\
\text { rubbish bin, small circuit walking path, } 1 \\
\text { enclosed dog off-lead area with drinking } \\
\text { fountain }\end{array}$ & $7061(29.7)$ & $26 \%$ & $47 \%$ & $\begin{array}{l}35091 \\
(26.91)\end{array}$ & 36 years & $\$ 865$ & St. Albans \\
\hline \multicolumn{11}{|c|}{$\begin{array}{l}\text { Park catchment data are for relevant statistical local areas near the parks including where the residents' surveys were delivered. } \\
\text { Population density data in persons per hectares. } \\
\text { *Park size from Brimbank City Council records. } \\
\text { †Park catchment data from Australian Bureau of Statistics (ABS) } 2011 \text { census data in table builder (collated for relevant statistical local areas). } \\
\text { fSuburb data from ABS } 2011 \text { census quick stats by Statistical Local Area: http://www.abs.gov.au/websitedbs/censushome.nsf/home/quickstats?opendocument\&navpos=220. } \\
\text { §Suburb data for population density from Brimbank City Council community profile id data for suburbs in } 2011 \text { census: St Albans: http://profile.id.com.au/brimbank/about?WebID=310; Keilor: } \\
\text { http://profile.id.com.au/s_keilor/population-density Sunshine West: http://profile.id.com.au/brimbank/about?WebID=280 Sunshine: http://profile.id.com.au/brimbank/about?WebID=260. } \\
\text { C, Comparison; Ix, Intervention. }\end{array}$} \\
\hline
\end{tabular}


Figure 2 Amenities at study parks $\left(t_{2}\right)$ and $\left(t_{3}\right)$.

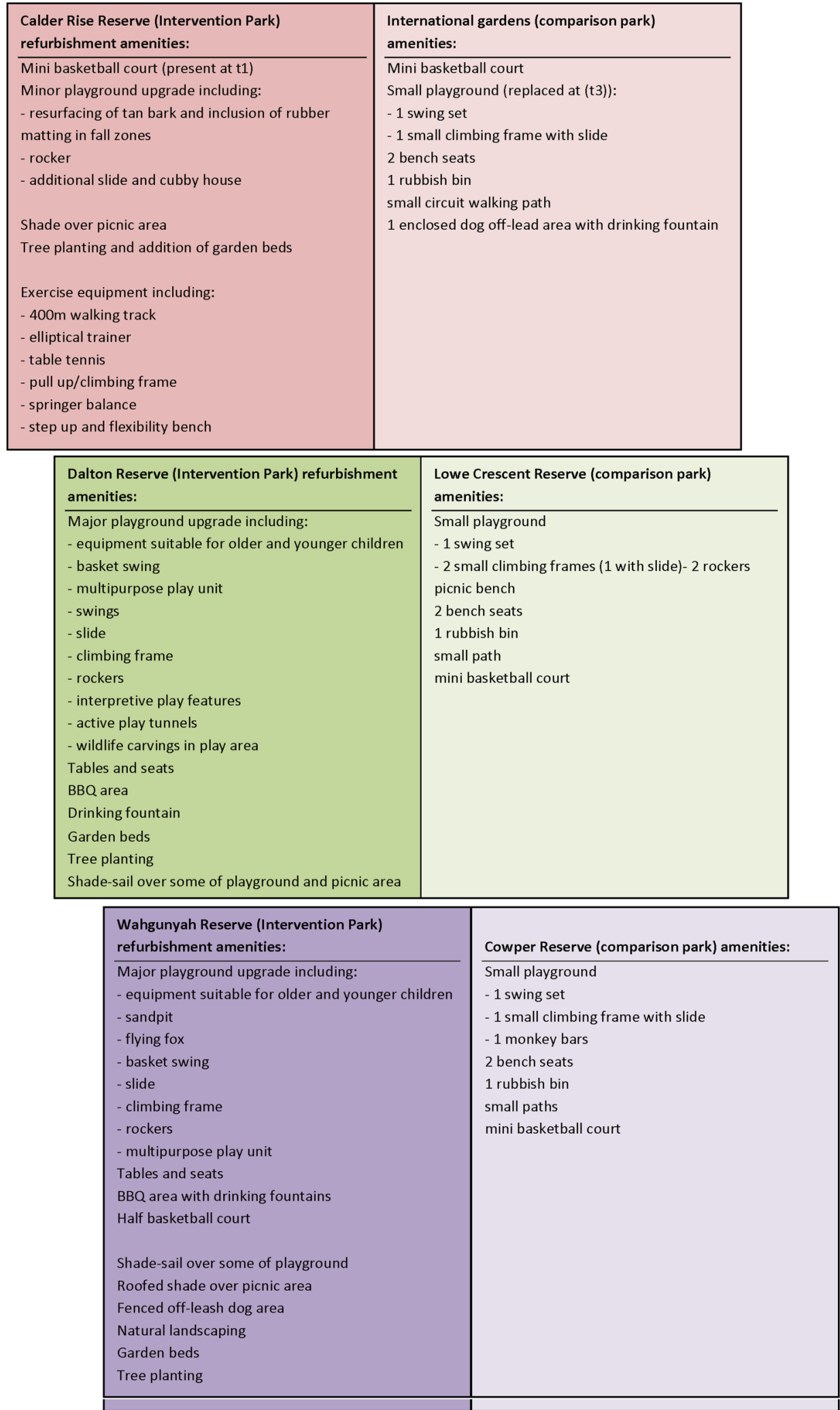

portable shade) within the park (refer online supplementary appendix 2 for Audit tool). This involved assessing the amount and usability of shade provided by each source at key areas of the park (over playground equipment, playground seating areas, $\mathrm{BBQ}$ areas and picnic tables). Audits were performed during peak UV times a few weeks prior to initiation of the park observations in November. 


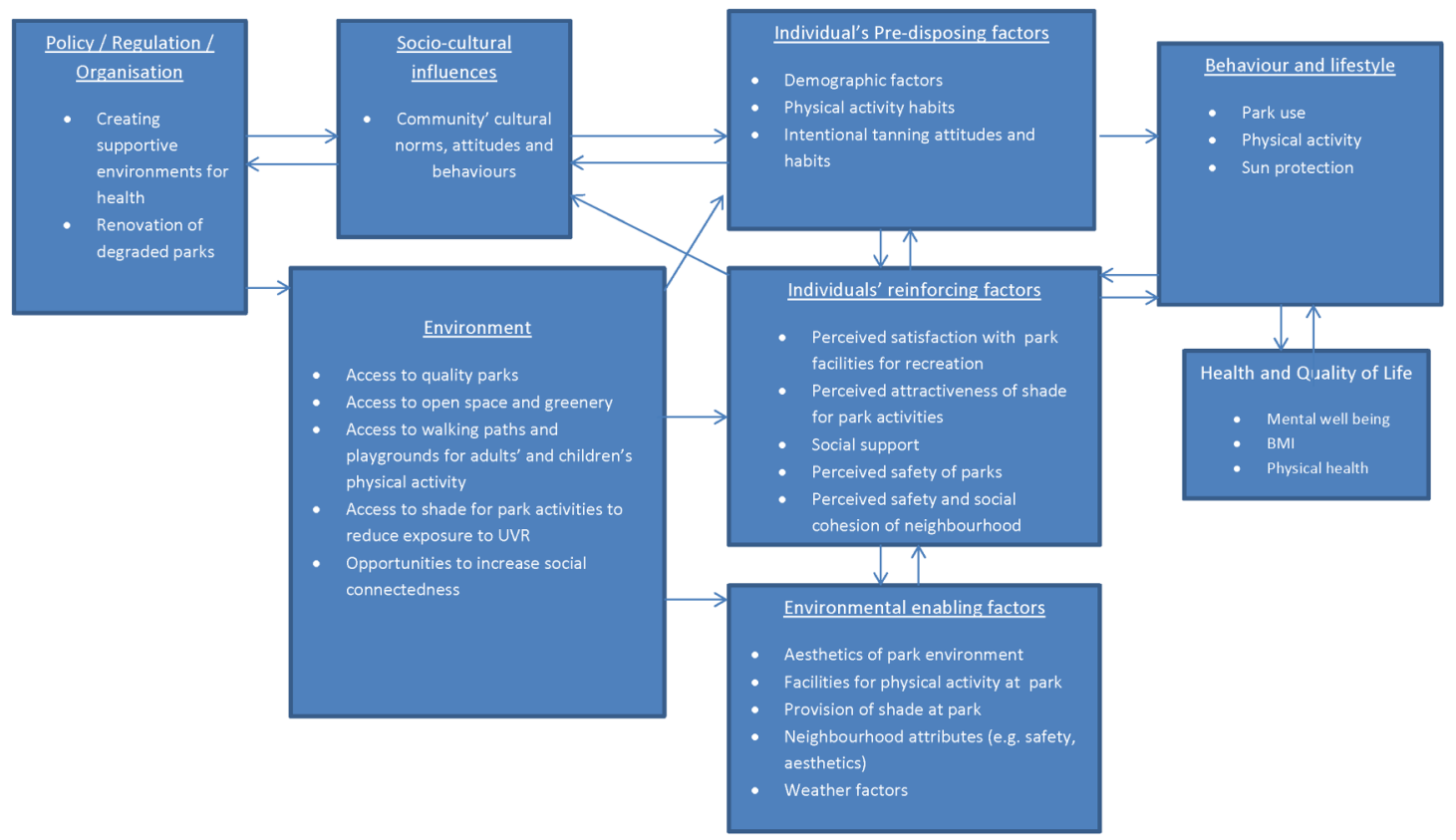

Figure 3 Factors potentially influencing the impact of the park renovations on behaviours in the context of broader socioecological models of health outcomes. BMI, body mass index; UVR, ultraviolet radiation.

\section{Park observations and intercept surveys}

The observations at the study parks were performed on 8 days across each test-period, with all parks observed on the same dates. The observation dates included one weekday and 1 weekend day each month from November to February (in the Southern hemisphere spring-summer). The observation dates were randomly selected from the first 2 weeks of each month. Contingency dates were randomly selected from the last 2 weeks of each month to replace any observation days that needed to be rescheduled due to cancellations from days of extreme weather (heavy rain or temperatures $\geq 35^{\circ}$ Celsius).

The inter-rater reliability of research staff observations was assessed during training using a sample of photos of people in parks. Research staff achieved $80 \%$ agreement prior to starting the data collection at the parks.

On each observation date, two research staff members were sitting together to make the study observations in an unobtrusive location in the park (at least $15 \mathrm{~m}$ distance from other park visitors where possible). The researchers could clearly observe the whole park from their position, as the parks were all of a relatively small size and had an absence of large trees and shrubs that would obscure their view. Each researcher was allocated to separately observe one of two study areas (the playground and the rest of the park). The research staff made systematic scans every 30 min of all park visitors in the study area during early morning (07:00-08:30), mid-day (11:30-13:00) and late afternoon (16:00-18:30). By sitting together, researchers made sure that they did not observe the same people during an observation scan, and each park visitor was only counted once per scan. A total of 11 scans were made at each park per day. The procedure for each scan was to sequentially (from left to right) observe each person as they came into view (momentarily) and record their gender, approximate age-group (child $<14,14-19,20-49,50+$ ), sun protection behaviours (type of hat, sunglasses, collar, sleeve-length, midriff cover, leg covering, extent and type of shade used including if using trees, a shadesail, other built-shade or portable shade) and the activity they were engaged in (ie, sitting, standing, walking or vigorous activity). The location in the park where the person's activity occurred (picnic and $\mathrm{BBQ}$ area, playground, walking path or rest of the park) was also recorded.

Local cloud-cover was assessed during park observations using a validated measure. ${ }^{46}$ Records of the ambient temperature at 15:00 as measured at the climate stations nearest the parks on the observation dates will be obtained from the Bureau of Meteorology to compare equivalence of temperature conditions across pretest $\left(\mathrm{t}_{1}\right)$, post-test $\left(\mathrm{t}_{2}\right)$ and follow-up $\left(\mathrm{t}_{3}\right)$.

At the end of early morning, mid-day and late afternoon observation periods, research staff approached park visitors (eligible if English speaking and 14 years or older) to conduct a brief (5-10 $\mathrm{min})$ self-report intercept survey. If more than one person was in the park, the RA endeavoured to recruit an equal number of men and women, and an equal number of teens, young adults and older adults. The participants were eligible to complete only one intercept survey during each testperiod. For several weeks at the end of each test-period, the project manager continued to recruit park visitors to complete the intercept survey on weekdays. The 
intercept surveys assessed respondents' activities at the park on the day (and activities for their child if they attended the park with them), the respondents' current emotional state (PANAS), intended duration at the park, mode of travelling to the park, frequency of use of the park and other parks, opportunities for socialising at the park, usual physical activity levels at the park, perceptions of the park environment (eg, rating the aesthetics, usefulness and condition of amenities, satisfaction with shade, perceived safety), demographic characteristics, dog ownership, physical well-being, community wellbeing and social cohesion (refer online supplementary appendix 1, eg, items). The intercept surveys were revised at post-test $\left(\mathrm{t}_{2}\right)$ and follow-up $\left(\mathrm{t}_{3}\right)$ to include additional measures of park visitors' participation in community events, perceptions of any changes to the park, suggestions for future improvements to the park and attendance at the park during the previous year. At post-test $\left(t_{2}\right)$, park visitors were asked for their perceptions of the park environment compared with the last/ spring summer $\left(t_{3}\right)$. Online supplementary appendix 1 describes the source and examples of each of the measures used in the intercept survey.

The intercept survey was completed anonymously. Although different people may have participated at pretest $\left(t_{1}\right)$, post-test $\left(t_{2}\right)$ and follow-up $\left(t_{3}\right)$, questions were included to indicate if they had completed surveys at $\left(\mathrm{t}_{2}\right)$ and/or $\left(\mathrm{t}_{3}\right)$.

\section{Residents' surveys}

The residents' surveys were delivered by the research staff to residents' letter boxes at the end of the first two summers (during February to March). Catchment areas containing $\sim 1000$ households within $1 \mathrm{~km}$ from each park were identified with the assistance of a Brimbank City Council Urban Designer. The urban fabric surrounding each park, such as main roads that may limit access by residents, was taken into consideration when defining the catchment boundaries in order to include households most likely to be potential users of the park. Resident survey packages were delivered to each household within these catchment areas (ie, targeting the same houses for delivery during pretest $\left(t_{1}\right)$ and post-test $\left.\left(\mathrm{t}_{2}\right)\right)$.

The survey was completed anonymously by one household member aged 14 years or older. Parents or guardians were also asked to provide reports for one child under 14 years of age, with whom they most recently attended their local park. If more than one child attended, they provided reports for the child with the next birthday. A letter (with partner's logos) outlining the survey purpose along with a reply-paid envelope was enclosed in an envelope with a sticker on the front highlighting that the material was for the purpose of research and that survey participation entitled them to enter a raffle to win retail vouchers (pretest $\left(t_{1}\right)$ : $1 \times \$ 500$; post-test $\left(\mathrm{t}_{2}\right): 1 \times \$ 250$ and $\left.2 \times \$ 150\right)$.
The residents' survey assessed respondents' demographics (including age, skin type, education and country of birth), study park use, usual physical activity at the study park and other parks, awareness of park facilities, perceived park aesthetics, satisfaction with shade provided, access to the park, neighbourhood satisfaction, neighbourhood social support/social cohesion, personal safety in neighbourhood, physical and psychological well-being, leisure-time physical activity and intentional tanning attitudes and behaviours, perceived skin cancer risk and attitude towards using shade (refer online supplementary appendix 1 , eg, items).

Participants from each park catchment may have completed a pretest $\left(t_{1}\right)$ and/or a post-test $\left(t_{2}\right)$ resident survey. A question was included in the post-test residents' survey to assess if they completed the pre-test $\left(t_{1}\right)$ survey or not.

\section{Focus groups}

We are also using qualitative methods to explore the perceived impact and acceptability of the intervention components with local residents and park visitors aged 14 years or older. We planned to conduct two $90 \mathrm{~min}$ focus groups for each intervention park after post-test $\left(t_{2}\right)$ and follow-up $\left(t_{3}\right)$. The focus groups will use a semistructured question guide to investigate participants' perceptions of the park, perceived barriers to park use, acceptability of specific refurbishments, preferred park facilities and recommendations for other changes to the park. The focus groups will be held at locations near the study parks and facilitated by the project manager. The discussions will be recorded using a digital audio recorder (for transcription) and summarised by a note-taker.

The first round of focus groups ( $\left.t_{2}\right)$ is completed, while recruitment and conduct of further focus groups for the follow-up $\left(t_{3}\right)$ to explore perceived long-term acceptability of the refurbishments has started. Participants were recruited via a letter delivered to residents' letter boxes in the park catchment areas (described earlier), or via signs displayed in the study parks. The recruitment material included a brief description of the topics for discussion, offered an incentive for participation of a $\$ 80$ retail voucher and the contact details of the project manager. Although recruitment for the first round of focus groups proved difficult, with only 5 focus groups with 24 participants in total held during autumn-winter 2015, more people have expressed an interest in participating this year (2016).

\section{Impact evaluation}

Primary outcomes and analyses

Our primary outcomes and analyses will be based on the park observation and intercept data. The primary outcomes to be assessed are: (1) the mean number of people observed in the park and self-reported frequency of park usage; (2) the mean number of people observed 
using shade; and (3) the mean number of people observed in parks who are engaged in active recreation (ie, the number of people engaged in walking or moderate or vigorous physical activity).

The primary analysis of intervention impact will be assessed by analysing the intention-to-treat group differences in changes from pretest $\left(t_{1}\right)$ to post-test $\left(t_{2}\right)$ in the primary outcomes (listed above). The primary analysis is based on comparing change only in group outcomes from pretest $\left(\mathrm{t}_{1}\right)$ to post-test $\left(\mathrm{t}_{2}\right)$, first aggregated at the park (cluster level) for each test-period. Owing to the study design (as-if random assignment), ${ }^{47}$ no adjustments will be made for any variables (covariates) in the primary analysis. Each hypothesis will be assessed by a one sample t-test; for example, comparing the mean change in number of people observed using the intervention parks (per park, per test period) minus the mean change in number of people observed using the comparison parks (per park, per test period).

Study power was estimated for two-sided tests with a probability of type I error of 5\% using the "sampsi" command in Stata V.10.1 (StataCorp, College Station, Texas, USA). On the basis of previous research, we assumed an average park use of three individuals per 1.5 hours $^{26}$ and a variation in the mean difference in pretest $\left(\mathrm{t}_{1}\right)$ to post-test $\left(\mathrm{t}_{2}\right)$ usage of study areas for a built-shade intervention of $\mathrm{SD}=3.5 .^{30} 48$ For the proposed analysis, assuming two-tailed tests with a type I error rate of 0.05 , we would expect to have an $80 \%$ power to detect an increase of 5.6 or more individuals in the intervention parks from pretest $\left(\mathrm{t}_{1}\right)$ to post-test $\left(\mathrm{t}_{2}\right)$ compared with the comparison parks. This represents power to detect a near threefold increase in usage of intervention parks, which is a smaller increase than that shown by the previous study, ${ }^{26}$ which showed a near fourfold increase in usage of the intervention park compared with the comparison park.

\section{Secondary analyses}

We plan to conduct a number of secondary analyses to further explore the impact of the intervention:

1. We will conduct analyses to examine the impact on secondary outcomes for park visitors (eg, selfreported psychological well-being of park visitors, perceived social connectedness/community engagement) and acceptability measures (eg, perceived aesthetics of the park amenities). Responses to the individual items in the PANAS will be summed to compute continuous scores of negative (eg, 'upset' coded 1: very slightly or not at all to 5: extremely) and positive emotional state items (eg, 'relaxed' coded 1: very slightly or not at all to 5: extremely) for participants at the park. Social connectedness will be assessed by responses to two individual items on the frequency of times respondents met or talked to new people and to their neighbours or other people they know at the park. A score summing six items (coded 1: strongly disagree to 5: strongly agree) about park visitors' sense of belonging and participation in their local community will be used to assess community engagement. Perceived aesthetics will be assessed based on park visitors' ratings (coded 1: not attractive to 10: very attractive) of the individual park amenities present at both pretest $\left(\mathrm{t}_{1}\right)$ and post-test $\left(\mathrm{t}_{2}\right)(\mathrm{eg}$, walking paths, playground) and the park overall. These will be analysed in a similar manner to the primary analyses on an intention-to-treat basis, comparing pretest $\left(t_{1}\right)$ to post-test $\left(t_{2}\right)$ difference scores for the intervention and control groups (aggregated by park per test period) using an unpaired t-test for each. Additionally, descriptive analyses (no statistical tests to minimise type 1 errors) will be used to explore potential impact on all other observation (eg, observed sun protection and extent of shade used at the park) and self-report measures (eg, reported park access, leisure time physical activity, sun protection habits, health status, perceived neighbourhood safety).

2. We will conduct sensitivity analyses to examine the impact on primary and secondary outcomes above based on the interventions received.

3. We will conduct a sensitivity analysis on primary outcomes, as suggested in guides to analysis of natural experiments, ${ }^{47} 49$ to adjust for potential confounding group differences at baseline that may influence exposure to the intervention or outcomes (ie, park use). A random effects model (with treatment group and survey year as predictor variables) will be used to adjust for any variation in the characteristics of the park catchment populations (relevant SA1s) that might influence park use. We specify an a priori population density, proportion of children and income (proportion of residents with $\$ 590$ or less weekly personal income) within park catchment populations as likely to influence park use. We will review baseline group differences in residents' perceptions of the aesthetics of the park, and if this differs in magnitude greater than one SD, we will also adjust for perceived aesthetics in analyses of park use. Similarly, we will review if weather conditions (cloud cover and temperature) vary across the study parks on the observation dates, given that this may influence park use, physical activity and shade use.

4. We will test the sustainability of any group differences on primary outcomes in the second spring-summer after refurbishments (follow-up $\left(t_{3}\right)$ ). Analyses comparing pretest $\left(\mathrm{t}_{1}\right)$ and follow-up $\left(\mathrm{t}_{3}\right)$ and comparing post-test $\left(\mathrm{t}_{2}\right)$ and follow-up $\left(\mathrm{t}_{3}\right)$ differences will be performed.

5. We will examine the possibility of a 'gentrification' effect comparing park catchment median income in intervening years if sufficiently detailed census data are available in 2011 and 2016.

Stata and SPSS will be used for the analyses. Multiple imputation, with study group and test-period as covariates, will be used to replace missing data in analyses. 


\section{Qualitative analysis}

We will use qualitative analysis (using Nvivo software) to assess recurrent themes ${ }^{50}$ in the focus group discussions to describe local residents' and park goers' opinions about the park refurbishments, including perceived barriers to park use, acceptability of the newly developed park features, perceptions of the durability of the refurbishments, their preferred amenities at parks and recommendations for park changes.

\section{Process evaluation}

The audit data will be used to describe the intervention components implemented at each park and any changes to the comparison parks. Analysis of self-reported residents' and park visitors' use of other parks will be used to assess study contamination (use of other study parks). Research staff will also collate information on construction progress, park open days and events, and damage or vandalism to facilities. Positive and negative comments from park visitors and local residents on the intervention components will also be collated from the surveys and focus groups.

\section{ETHICS/DISSEMINATION}

The ShadePlus intervention study was approved by Cancer Council Victoria's Human Research Ethics Committee. Special requirements for the study observations included displaying a sign at the park entrance to advise park visitors that the study was occurring. Park signs were erected at each intervention and control park to advise park users that a research study was being conducted about 'visitor use'. The sign did not mention the intervention. We anticipate that the sign would have minimal impact on park behaviour; however, it might make some people reluctant to use the parks. Recruitment of pairs of female research assistants for the observations was also required, given that the study measures involved observation of children in the park for extended periods across the day.

In addition to the planned preparation of papers for peer-review publication, the inclusion of our local government partner and a steering committee with peak government agencies in this research will facilitate dissemination of the study findings through established urban planning networks.

\section{DISCUSSION}

Park refurbishments have the potential to address inequity in provision of quality park facilities for communities living in socioeconomically disadvantaged areas. Studies such as ShadePlus can improve understanding of the broader effects of park refurbishments in these types of areas. To the best of our knowledge, ShadePlus is the first study evaluating the effects of modifying the built environment on both physical activity levels and sun protection behaviours, as well as social connectedness and psychological well-being. This extends previous studies examining the effects of providing purpose-built shade $^{3048}$ and of other park refurbishments on physical activity. ${ }^{24}{ }^{26}$ It is expected that the provision of shade in the park refurbishments will enable reduction in exposure to UVR, as well as increase usage of the playground and recreation amenities during hot weather.

We anticipate that this type of evidence will be particularly valuable for local councils when managing competing infrastructure needs in their local communities. Rather than seeing beautification of parks and facilities as simply aesthetic or of transitory benefit, evidence from trials such as ours may assist councils to attribute greater benefit of park refurbishment to more tangible longerterm benefits to the community. The initial costs of refurbishment can be placed in the context of promoting the health and well-being of a community in the long term. If, however, such facilities are shown to be of limited value to the health behaviours of a community, then the funding may be spent on alternative facilities or priorities, or justified by meeting other community needs.

\section{Author affiliations}

${ }^{1}$ Cancer Council Victoria, Melbourne, Victoria, Australia

${ }^{2}$ Deakin University, Institute for Physical Activity and Nutrition (IPAN), School of Exercise and Nutrition Sciences, Geelong, Australia

${ }^{3}$ Deakin University, School of Psychology, Faculty of Health, Geelong, Victoria, Australia

${ }^{4}$ University of Melbourne, Centre for Epidemiology and Biostatistics, Melbourne, Victoria, Australia

Acknowledgements The authors thank Brimbank City Council, in particular Adrian Gray (Manager Urban Design), for the partnership in this research study and for implementing the intervention. The authors also thank the Municipal Association of Victoria and Victorian Department of Human Services for their support of the study, the many research assistants and administrative staff who worked on this project.

Contributors SJD, JV, JSa, MW, PKS and RJM participated in the study design. SJD, JV, JSa, MW, PKS and JSi participated in developing the core survey instruments. SJD wrote the manuscript drafts. All authors reviewed and revised the manuscript for important intellectual content and approved its submission for publication. Each author was involved in writing the study protocol.

Funding This study was funded by the National Health and Medical Research Council Partnership Research Project ID 1062314, with partner Brimbank City Council). JV is supported by a National Health and Medical Research Council Early Career Fellowship (ID 1053426). JS and MW are supported by an Australian National Health and Medical Research Council Principal Research Fellowship (Salmon: ID 1026216; Wakefield: ID 1109720).

Competing interests None declared.

Ethics approval This study was approved by Cancer Council Victoria's Human Research Ethics Committee.

Provenance and peer review Not commissioned; externally peer reviewed.

Open Access This is an Open Access article distributed in accordance with the Creative Commons Attribution Non Commercial (CC BY-NC 4.0) license, which permits others to distribute, remix, adapt, build upon this work noncommercially, and license their derivative works on different terms, provided the original work is properly cited and the use is non-commercial. See: http:// creativecommons.org/licenses/by-nc/4.0/ 


\section{REFERENCES}

1. Dobbins $\mathrm{M}$, Husson $\mathrm{H}$, DeCorby $\mathrm{K}$, et al. School-based physical activity programs for promoting physical activity and fitness in children and adolescents aged 6 to 18. Cochrane Database Syst Rev 2013;2:CD007651

2. Lee IM, Shiroma EJ, Lobelo F, et al. Effect of physical inactivity on major non-communicable diseases worldwide: an analysis of burden of disease and life expectancy. Lancet 2012;380:219-29.

3. Weinstock MA. The struggle for primary prevention of skin cancer. Am J Prev Med 2008;34:171-2.

4. Bedimo-Rung AL, Mowen AJ, Cohen DA. The significance of parks to physical activity and public health: a conceptual model. Am J Prev Med 2005;28(2 Suppl 2):159-68.

5. Oreskovic NM, Perrin JM, Robinson Al, et al. Adolescents' use of the built environment for physical activity. BMC Public Health 2015;15:251.

6. Coups EJ, Manne SL, Heckman CJ. Multiple skin cancer risk behaviors in the U.S population. Am J Prev Med 2008;34:87-93.

7. Fransen $M$, Karahalios $A$, Sharma $N$, et al. Non-melanoma skin cancer in Australia. Med J Aust 2012;197:565-8.

8. Rodríguez DA, Cho G-H, Evenson KR, et al. Out and about: association of the built environment with physical activity behaviors of adolescent females. Health Place 2012;18:55-62.

9. Grow HM, Saelens BE, Kerr J, et al. Where are youth active? Roles of proximity, active transport, and built environment. Med Sci Sports Exerc 2008;40:2071-9.

10. Almanza E, Jerrett M, Dunton $\mathrm{G}$, et al. A study of community design, greenness, and physical activity in children using satellite, GPS and accelerometer data. Health Place 2012;18:46-54

11. Sallis JF, Cerin E, Conway TL, et al. Physical activity in relation to urban environments in 14 cities worldwide: a cross-sectional study. Lancet 2016;387:2207-17.

12. Veitch J, Carver A, Abbott G, et al. How active are people in metropolitan parks? An observational study of park visitation in Australia. BMC Public Health 2015;15:610.

13. Stigsdotter UK, Ekholm O, Schipperijn J, et al. Health promoting outdoor environments-associations between green space, and health, health-related quality of life and stress based on a Danish national representative survey. Scand J Public Health 2010;38:411-7.

14. Crawford D, Timperio A, Giles-Corti B, et al. Do features of public open spaces vary according to neighbourhood socioeconomic status? Health Place 2008;14:889-93.

15. Kavanagh AM, Goller JL, King T, et al. Urban area disadvantage and physical activity: a multilevel study in Melbourne, Australia. $J$ Epidemiol Community Health 2005;59:934-40.

16. Turrell G, Mathers $C$. Socioeconomic inequalities in all-cause and specific-cause mortality in Australia: 1985-1987 and 1995-1997. Int $J$ Epidemiol 2001;30:231-9.

17. Oldenburg B, McGuffog ID, Turrell G. Socioeconomic determinants of health in Australia: policy responses and intervention options. Med J Aust 2000;172:489-92.

18. Armstrong BK, Gillespie JA, Leeder SR, et al. Challenges in health and healthcare for Australia. Med J Aust 2007;187:485-9.

19. Sallis JF, Owen N. Ecological models. In: Glanz K, Lewis FM, Rime BK, eds. Health behavior and health education: theory, research, and practice. 2nd edn. San Francisco: Jossey-Bass Publishers, 1997:403-24

20. McLeroy KR, Bibeau D, Steckler A, et al. An ecological perspective on health promotion programs. Health Educ Q 1988;15:351-77.

21. Sallis JF, Floyd MF, Rodriguez DA, et al. Role of built environments in physical activity, obesity, and cardiovascular disease. Circulation 2012;125:729-37.

22. World Health Organisation. Ottawa charter for health promotion. Can J Public Health 1986;77:425-6.

23. Northridge ME, Sclar ED, Biswas P. Sorting out the connections between the built environment and health: a conceptual framework for navigating pathways and planning healthy cities. $J$ Urban Health 2003;80:556-68.

24. Hunter RF, Christian H, Veitch J, et al. The impact of interventions to promote physical activity in urban green space: a systematic review and recommendations for future research. Soc Sci Med 2015;124:246-56.

25. Audrey S, Batista-Ferrer $\mathrm{H}$. Healthy urban environments for children and young people: a systematic review of intervention studies. Health Place 2015;36:97-117.

26. Veitch J, Ball K, Crawford D, et al. Park improvements and park activity: a natural experiment. Am J Prev Med 2012;42:616-9.

27. Cohen DA, Marsh T, Williamson S, et al. Impact and cost-effectiveness of family fitness zones: a natural experiment in urban public parks. Health Place 2012;18:39-45.
28. Bohn-Goldbaum EE, Phongsavan P, Merom D, et al. Does playground improvement increase physical activity among children? A quasi-experimental study of a natural experiment. $J$ Environ Public Health 2013;2013:109841.

29. Tester J, Baker R. Making the playfields even: evaluating the impact of an environmental intervention on park use and physical activity. Prev Med 2009;48:316-20.

30. Dobbinson SJ, White V, Wakefield MA, et al. Adolescents' use of purpose built shade in secondary schools: cluster randomised controlled trial. BMJ 2009;338:b95

31. Dobbinson SJ, Jamsen K, Francis K, et al. Trends in Australians' skin cancer prevention behaviours: Findings of the 2006-07 national sun protection survey (not for citation in websites or peer review literature without authors permission). Population Health Congress. Brisbane, Australia, 2008

32. Besenyi GM, Kaczynski AT, Wilhelm Stanis SA, et al. Demographic variations in observed energy expenditure across park activity areas. Prev Med 2013;56:79-81.

33. Dobbinson S, Niven $\mathrm{P}$, Buller D, et al. Comparing handheld meters and electronic dosimeters for measuring ultraviolet levels under shade and in the Sun. Photochem Photobiol 2016;92:208-14.

34. Tucker P, Gilliland J, Irwin JD. Splashpads, swings, and shade: parents' preferences for neighbourhood parks. Can J Public Health 2007;98:198-202.

35. Potwarka LR, Kaczynski AT, Flack AL. Places to play: association of park space and facilities with healthy weight status among children. $J$ Community Health 2008;33:344-50.

36. Timperio A, Giles-Corti B, Crawford D, et al. Features of public open spaces and physical activity among children: findings from the CLAN study. Prev Med 2008;47:514-8.

37. Kaczynski AT, Besenyi GM, Stanis SA, et al. Are park proximity and park features related to park use and park-based physical activity among adults? Variations by multiple sociodemographic characteristics. Int J Behav Nutr Phys Act 2014;11:146.

38. Brimbank City Council. The Diverse Communities of Brimbank. Sunshine, Victoria. https://www.yumpu.com/en/document/view/ 32007840/the-diverse-communities-of-brimbank-profile-brimbankcity-council

39. McKenzie TL, Cohen DA, Sehgal A, et al. System for Observing Play and Recreation in Communities (SOPARC): reliability and feasibility measures. J Phys Act Health 2006;3(Suppl 1): S208-S22.

40. Evenson KR, Jones SA, Holliday KM, et al. Park characteristics, use, and physical activity: a review of studies using SOPARC (System for Observing Play and Recreation in Communities). Prev Med 2016;86:153-66.

41. Lagerlund M, Dixon HG, Simpson JA, et al. Observed use of sunglasses in public outdoor settings around Melbourne, Australia: 1993 to 2002. Prev Med 2006;42:291-6.

42. Dixon HG, Lagerlund M, Spittal MJ, et al. Use of sun-protective clothing at outdoor leisure settings from 1992 to 2002: serial cross-sectional observation survey. Cancer Epidemiol Biomarkers Prev 2008;17:428-34

43. Watson D, Clark LA, Tellegen A. Development and validation of brief measures of positive and negative affect: the PANAS scales. J Pers Soc Psychol 1988:54:1063-70.

44. Watson D, Clark LA. The PANAS-X: Manual for the Positive and Negative Affect Schedule-Expanded Form Secondary The PANAS-X: Manual for the Positive and Negative Affect ScheduleExpanded Form. 1994. http://ir.uiowa.edu/cgi/viewcontent.cgi? article $=1011 \&$ context $=$ psychology pubs

45. Tennant R, Hiller L, Fishwick R, et al. The Warwick-Edinburgh Mental Well-being Scale (WEMWBS): development and UK validation. Health Qual Life Outcomes 2007;5:63.

46. Andersen PA, Buller DB, Walkosz BJ, et al. Environmental variables associated with vacationers' sun protection at warm weather resorts in North America. Environ Res 2016;146:200-6.

47. Medical Research Council. Using natural experiments to evaluate population health interventions: guidance for producers and users of evidence. London: MRC, 2011.

48. Dobbinson S, Jamsen K, McLeod K, et al. Maximising students' use of purpose-built shade in secondary schools: quantitative and qualitative results of a built-environment intervention. Health Place 2014;26:136-42.

49. Craig $P$, Cooper $C$, Gunnell $D$, et al. Using natural experiments to evaluate population health interventions: new Medical Research Council guidance. J Epidemiol Community Health 2012;66: 1182-6.

50. Green J, Willis K, Hughes E, et al. Generating best evidence from qualitative research: the role of data analysis. Aust $N Z J$ Public Health 2007;31:545-50. 